\title{
Article \\ Combined In Silico, Ex Vivo, and In Vivo Assessment of L-17, a Thiadiazine Derivative with Putative Neuro- and Cardioprotective and Antidepressant Effects
}

\author{
Alexey Sarapultsev 1,2,*(D), Pavel Vassiliev ${ }^{3}$, Daniil Grinchii ${ }^{4}$, Alexander Kiss ${ }^{5}$, Mojmir Mach ${ }^{6} \mathbb{D}^{\circ}, J_{a n a}$ Osacka ${ }^{5} \mathbb{D}$, \\ Alexandra Balloova ${ }^{6}$, Ruslan Paliokha ${ }^{4}$, Andrey Kochetkov ${ }^{3}$, Larisa Sidorova ${ }^{7}$, Petr Sarapultsev ${ }^{1}$, \\ Oleg Chupakhin ${ }^{7,8}$, Maxim Rantsev ${ }^{9}$, Alexander Spasov ${ }^{3}$ and Eliyahu Dremencov $4,5, *$ (D)
}

Citation: Sarapultsev, A.; Vassiliev, P.; Grinchii, D.; Kiss, A.; Mach, M.; Osacka, J.; Balloova, A.; Paliokha, R.; Kochetkov, A.; Sidorova, L.; et al. Combined In Silico, Ex Vivo, and In Vivo Assessment of L-17, a

Thiadiazine Derivative with Putative Neuro- and Cardioprotective and Antidepressant Effects. Int. J. Mol. Sci. 2021, 22, 13626. https://doi.org/ $10.3390 /$ ijms222413626

Academic Editor: Elek Molnár

Received: 7 November 2021

Accepted: 12 December 2021

Published: 20 December 2021

Publisher's Note: MDPI stays neutral with regard to jurisdictional claims in published maps and institutional affiliations.

Copyright: (c) 2021 by the authors. Licensee MDPI, Basel, Switzerland. This article is an open access article distributed under the terms and conditions of the Creative Commons Attribution (CC BY) license (https:// creativecommons.org/licenses/by/ $4.0 /)$.
1 Institute of Immunology and Physiology of the Ural Branch of RAS, Pervomayskaya 106, 620049 Ekaterinburg, Russia; p.sarapultsev@gmail.com

2 School of Medical Biology, South Ural State University, Lenina 76, 454080 Chelyabinsk, Russia

3 Department of Pharmacology and Bioinformatics, Volgograd State Medical University, Pavshikh Bortsov Square 1, 400131 Volgograd, Russia; pvassiliev@mail.ru (P.V.); akocha@mail.ru (A.K.); aspasov@mail.ru (A.S.)

4 Center of Biosciences, Institute of Molecular Physiology and Genetics, Slovak Academy of Sciences, Dúbravská Cesta 9, 84005 Bratislava, Slovakia; daniil.grinchii@savba.sk (D.G.); Ruslan.Paliokha@savba.sk (R.P.)

5 Biomedical Research Center, Institute of Experimental Endocrinology, Slovak Academy of Sciences, Dúbravská Cesta 9, 84505 Bratislava, Slovakia; Alexander.Kiss@savba.sk (A.K.); Jana.Bundzikova@savba.sk (J.O.)

6 Center of Experimental Medicine, Institute of Experimental Pharmacology and Toxicology, Slovak Academy of Sciences, Dúbravská Cesta 9, 84004 Bratislava, Slovakia; mojmir.mach@savba.sk (M.M.); Alexandra.Balloova@savba.sk (A.B.)

7 Ural Federal University named after the First President of Russia B. N. Yeltsin, 19 Mira Street, 620002 Ekaterinburg, Russia; vlapp@isnet.ru (L.S.); chupakhin@ios.uran.ru (O.C.)

8 The IJ Postovsky Institute of Organic Synthesis of the Ural Branch of RAS, Akademicheskaya/S. Kovalevskoi, 22/20, 620990 Ekaterinburg, Russia

9 Ural State Medical University, Repina 3, 620014 Ekaterinburg, Russia; r-ma@bk.ru

* Correspondence: a.sarapultsev@gmail.com (A.S.); eliyahu.dremencov@savba.sk (E.D.)

Abstract: Depression associated with poor general medical condition, such as post-stroke (PSD) or post-myocardial infarction (PMID) depression, is characterized by resistance to classical antidepressants. Special treatment strategies should thus be developed for these conditions. Our study aims to investigate the mechanism of action of 2-morpholino-5-phenyl-6H-1,3,4-thiadiazine, hydrobromide (L-17), a recently designed thiadiazine derivative with putative neuro- and cardioprotective and antidepressant-like effects, using combined in silico (for prediction of the molecular binding mechanisms), ex vivo (for assessment of the neural excitability using c-Fos immunocytochemistry), and in vivo (for direct examination of the neuronal excitability) methodological approaches. We found that the predicted binding affinities of L-17 to serotonin (5-HT) transporter (SERT) and 5- $\mathrm{HT}_{3}$ and $5-\mathrm{HT}_{1 \mathrm{~A}}$ receptors are compatible with selective 5-HT serotonin reuptake inhibitors (SSRIs) and antagonists of 5- $\mathrm{HT}_{3}$ and $5-\mathrm{HT}_{1 \mathrm{~A}}$ receptors, respectively. $\mathrm{L}-17$ robustly increased c-Fos immunoreactivity in the amygdala and decreased it in the hippocampus. L-17 dose-dependently inhibited 5-HT neurons of the dorsal raphe nucleus; this inhibition was partially reversed by the 5- $\mathrm{HT}_{1 \mathrm{~A}}$ antagonist WAY100135. We suggest that L-17 is a potent 5-HT reuptake inhibitor and partial antagonist of 5- $\mathrm{HT}_{3}$ and $5-\mathrm{HT}_{1 \mathrm{~A}}$ receptors; the effects of L-17 on amygdaloid and hippocampal excitability might be mediated via 5-HT, and putatively mediate the antidepressant-like effects of this drug. Since L-17 also possesses neuroand cardioprotective properties, it can be beneficial in PSD and PMID. Combined in silico predictions with ex vivo neurochemical and in vivo electrophysiological assessments might be a useful strategy for early assessment of the efficacy and neural mechanism of action of novel CNS drugs. 
Keywords: treatment-resistant depression; depression due to general medical condition; post-stroke depression; post-myocardial infarction (MI) depression; thiadizines; serotonin transporter (SERT); serotonin receptors $5-\mathrm{HT}_{3}$ and $5-\mathrm{HT}_{1 \mathrm{~A}}$; docking energy; binding affinity; binding mechanism; c-Fos immunohistochemistry; electrophysiology in vivo

\section{Introduction}

L-17 (2-morpholino-5-phenyl-6H-1,3,4-thiadiazine, hydrobromide; Figure 1) is a thiadiazine derivative, synthesized by cyclocondensation of $\alpha$-bromoacetophenone with the original morpholine-4-carbothionic acid hydrazide [1].

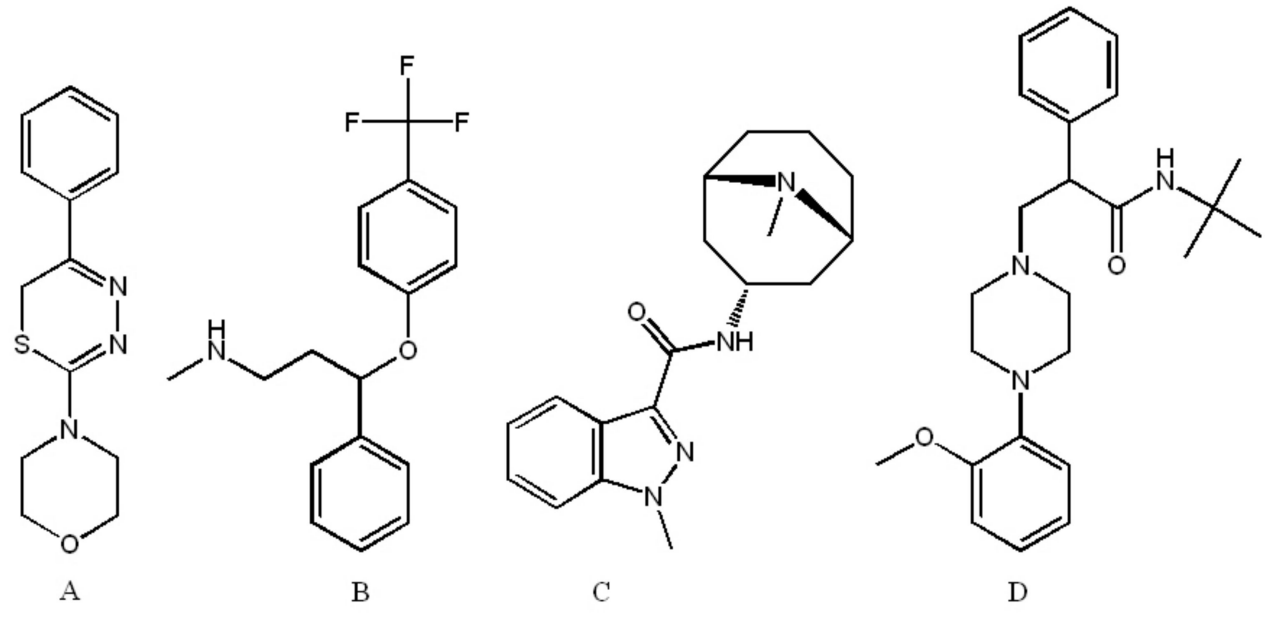

Figure 1. Structural chemical formulas of 2-morpholino-5-phenyl-6H-1,3,4-thiadiazine, hydrobromide: (L-17) (A), the SSRI fluoxetine (B), 5- $\mathrm{HT}_{3}$ receptor antagonist granisetron $(\mathbf{C})$, and $5-\mathrm{HT}_{1 \mathrm{~A}}$ receptor antagonist WAY100135 (D).

In our previous studies, we have shown, using animal models, a putative therapeutic effect of L-17 in myocardial infarction (MI) [2-4] and pancreatitis [5]. In these models, L-17 significantly decreased the initial infection area and accelerated the granulocytotic and suppressed cytokine component of the inflammatory reaction in rats after coagulation of the left coronary artery [2,3]. L-17 was also reported to attenuate the immune system response to immobilization stress in rats, suggesting an immunostimulatory effect of this compound during stress copying [4]. In addition, neuroprotective [1] and antidepressantlike [6] effects of L-17 in rats have been demonstrated. In this study, we aimed to investigate the mechanism of the putative beneficial effect of L-17 on the central nervous system (CNS), using a combination of in silico, Ex Vivo, and In Vivo methods [7].

For in silico assessments, we constructed a three-dimensional (3D) model of L-17; examined its interaction with different targets, such as serotonin (5-HT) transporter (SERT) and $5-\mathrm{HT}$ receptors 3 and $1 \mathrm{~A}\left(5-\mathrm{HT}_{3} / 5-\mathrm{HT}_{1 \mathrm{~A}}\right)$; and calculated the minimum binding energy. SERT and $5-\mathrm{HT}_{3}$ were chosen because they play a primary role in the pathophysiology and treatment of CNS disorders.

Immunohistochemical assessment of the proto-oncogene Fos across the brain is an Ex Vivo experimental technique used for the investigation of the mechanism of action of novel CNS drugs. The activation of the proto-oncogene Fos, resulting in an increased expression of its protein product c-Fos, is a well-established marker for neuronal excitability within a specific brain area [8-11]. Increased proto-oncogene Fos expression in the amygdala, indicating increased neural excitability in this brain area, has been observed after administration of various CNS drugs, such as typical [12] and atypical antipsychotics [12-14], tricyclic antidepressants [13], and selective serotonin reuptake inhibitors (SSRIs) [13,15,16]. 
The SSRI citalopram-induced increase in c-Fos immunoreactivity was shown to be potentiated by the selective antagonism of 5- $\mathrm{HT}_{1 \mathrm{~A}}$ receptors with WAY100638 [17], suggesting a key role of the 5-HT system in the modulation of amygdaloid excitability by CNS drugs. With regard to the prefrontal cortex (PFC), some SSRIs, such as fluvoxamine [16], and some atypical antipsychotics, such as olanzapine $[18,19]$, increased local c-Fos immunoreactivity. On the other hand, 5-HT depletion led to an increased c-Fos immunoreactivity in the PFC and hippocampus [20], suggesting that extracellular 5-HT suppresses neural excitability and Fos proto-oncogene expression in these brain areas.

Finally, we used single-unit extracellular electrophysiology In Vivo to examine the effect of L-17 on the excitability of 5-HT neurons in the dorsal raphe nucleus (DRN) of rats. Multiple antidepressant drugs, such as tricyclic antidepressants, SSRIs, dual 5-HT/norepinephrine, triple 5-HT/norepinephrine/dopamine reuptake inhibitors, pyridoindoles (experimental drugs with putative triple reuptake inhibition property), and some atypical antipsychotics, exhibit a potent acute inhibitory effect on the excitability of 5-HT neurons of the DRN. This inhibition is usually reversed by the selective 5- $\mathrm{HT}_{1 \mathrm{~A}}$ receptors antagonist, suggesting the involvement of the extracellular 5-HT. The assessment of the effect of an experimental CNS drug on the excitability of 5-HT neurons is a key marker for the preclinical assessment of its efficacy.

\section{Results}

\subsection{In Silico Predictions}

The following pharmacological activities were predicted for L-17 using PASS 10.4 Professional Extended software [21]: cognition disorders treatment $(\mathrm{Pa}=0.489, \mathrm{~Pa} / \mathrm{Pi}=27.17)$, phobic disorders treatment $(\mathrm{Pa}=0.703, \mathrm{~Pa} / \mathrm{Pi}=9.37)$, psychotropic $(\mathrm{Pa}=0.258, \mathrm{P} / \mathrm{Pi}=1.74)$, immunostimulant $(\mathrm{Pa}=0.191, \mathrm{~Pa} / \mathrm{Pi}=1.39)$, and antidepressant $(\mathrm{Pa}=0.162, \mathrm{~Pa} / \mathrm{Pi}=1.14)$. According to joint predictive evaluations in PASS and experimental data $[1,6]$, the most likely targeted activities corresponding to the serotoninergic effects of compound L-17 were suggested to be: $5-\mathrm{HT}_{3}$ antagonism $(\mathrm{Pa}=0.139, \mathrm{~Pa} / \mathrm{Pi}=1.17), 5-\mathrm{HT}$ release inhibition $(\mathrm{Pa}=0.225, \mathrm{~Pa} / \mathrm{Pi}=1.01)$, and $5-\mathrm{HT}$ reuptake blockade $(\mathrm{Pa}=0.470, \mathrm{~Pa} / \mathrm{Pi}=6.35)$. While the L-17 compound manifests as an atypical mild antipsychotic and antidepressant [1], for the subsequent analysis of its multitarget mechanism of action, the serotonin transporter (SERT) and the serotonin receptor types $3\left(5-\mathrm{HT}_{3}\right)$ and $1 \mathrm{~A}\left(5-\mathrm{HT}_{1 \mathrm{~A}}\right)$ were chosen as target proteins (Table 1).

Table 1. Docking energy $(\Delta \mathrm{E})$, binding affinity $(\mathrm{pK})$, and relevant affinity (RA) of L-17 to the SERT and 5- $\mathrm{HT}_{3} / 5-\mathrm{HT}_{1 \mathrm{~A}}$ receptors, compared to the SSRIs fluoxetine, granisetron, and WAY100135.

\begin{tabular}{|c|c|c|c|c|c|c|c|c|c|}
\hline \multirow{2}{*}{$\begin{array}{c}\text { Target } \\
\text { Molecule }\end{array}$} & \multicolumn{3}{|c|}{ SERT } & \multicolumn{3}{|c|}{$5-\mathrm{HT}_{3}$} & \multicolumn{3}{|c|}{$5-\mathrm{HT}_{1 \mathrm{~A}}$} \\
\hline & $\Delta \mathrm{E}, \mathrm{kcal} / \mathrm{mol}$ & pK & RA & $\Delta \mathrm{E}, \mathrm{kcal} / \mathrm{mol}$ & pK & RA & $\Delta \mathrm{E}, \mathrm{kcal} / \mathrm{mol}$ & $\mathrm{pK}$ & RA \\
\hline L-17 & -8.1 & 5.90 & 0.87 & -6.6 & 4.81 & 0.94 & -7.9 & 5.78 & 0.85 \\
\hline Fluoxetine & -9.3 & 6.78 & - & - & - & - & - & - & - \\
\hline Granisetron & - & - & - & -7.0 & 5.10 & - & - & - & - \\
\hline WAY100135 & - & - & - & - & - & - & -9.3 & 6.78 & - \\
\hline
\end{tabular}

Figure 2 illustrates the binding mechanisms of L-17, fluoxetine, granisetron, and WAY100135 with the SERT and 5- $\mathrm{HT}_{3}$ and 5- $\mathrm{HT}_{1 \mathrm{~A}}$ receptors, predicted using LigandScout 4.2.1 software [22].

Figure 3 illustrates the poses of L-17, fluoxetine, granisetron, and WAY100135 within the binding sites of SERT and $5-\mathrm{HT}_{3}$ and $5-\mathrm{HT}_{1 \mathrm{~A}}$ receptors. 

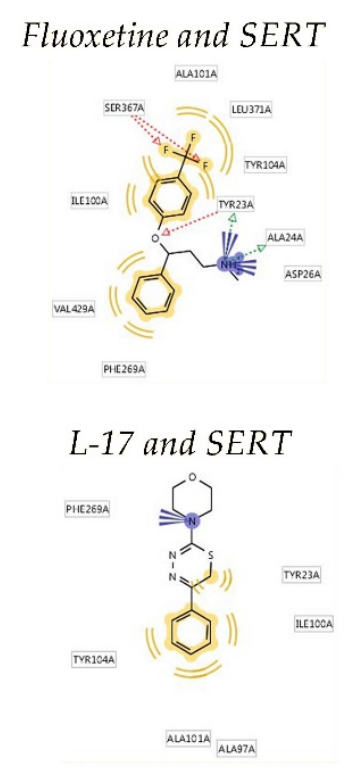

Granisetron and $5-H T_{3} R$

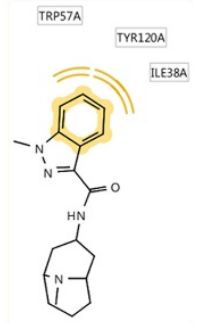

$$
L-17 \text { and } 5-H T_{3} R
$$

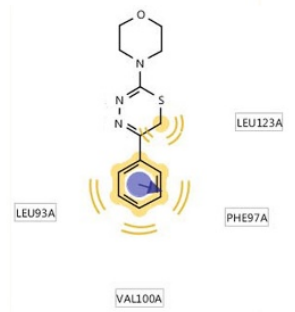

WAY100135 and $5-H T_{1 A} R$

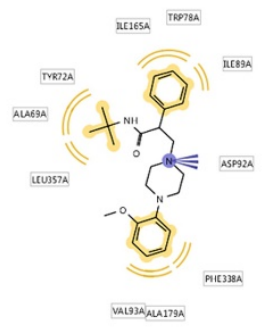

$L-17$ and $5-H T_{1 A} R$

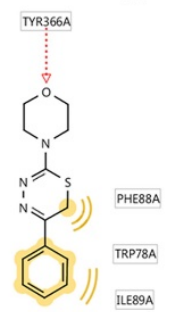

Figure 2. Binding of L-17, fluoxetine, granisetron, and WAY100135 to the SERT, and 5- $\mathrm{HT}_{3}\left(5-\mathrm{HT}_{3} \mathrm{R}\right)$ and $5-\mathrm{HT}_{1 \mathrm{~A}}\left(5-\mathrm{HT}_{1 \mathrm{~A}} \mathrm{R}\right)$ receptors.

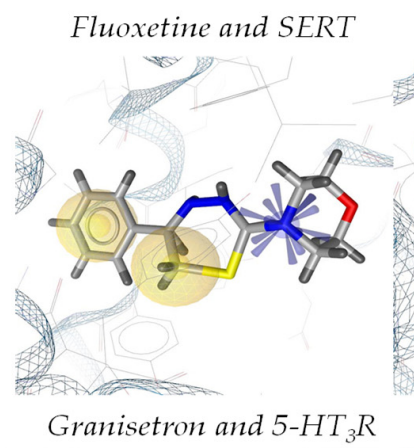

L-17 and SERT
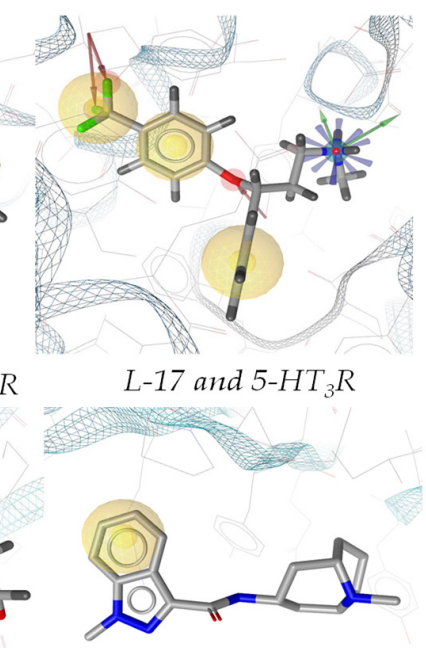

WAY100135 and 5-HT $T_{1 A} R \quad$ L-17 and 5-HT $T_{1 A} R$

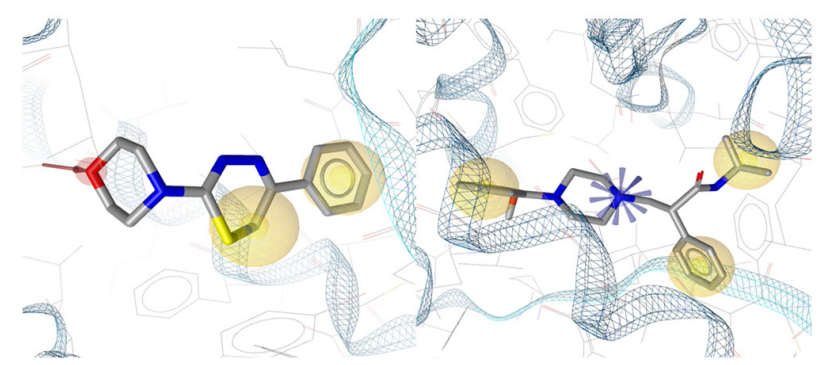

Figure 3. Poses of L-17, fluoxetine, granisetron, and WAY100135 within the binding sites of SERT, and $5-\mathrm{HT}_{3}$ and $5-\mathrm{HT}_{1 \mathrm{~A}}$ receptors. The pose of $\mathrm{L}-17$ within the SERT binding site is remarkably close to that of fluoxetine. There is also a partial similarity between L-17 and WAY100134 poses within the binding site of the $5-\mathrm{HT}_{1 \mathrm{~A}}$ receptor. The poses of $\mathrm{L}-17$ and granisetron within the binding site of the $5-\mathrm{HT}_{3}$ receptor are remarkably different. 


\subsection{Proto-Oncogene Fos Expression}

Figure 4 illustrates the expression of proto-oncogene Fos in three selected brain areas, including the prefrontal cortex (PFC, A-C), hippocampus (D-F), and amygdala (G-I) of vehicle- and L-17-pretreated rats:
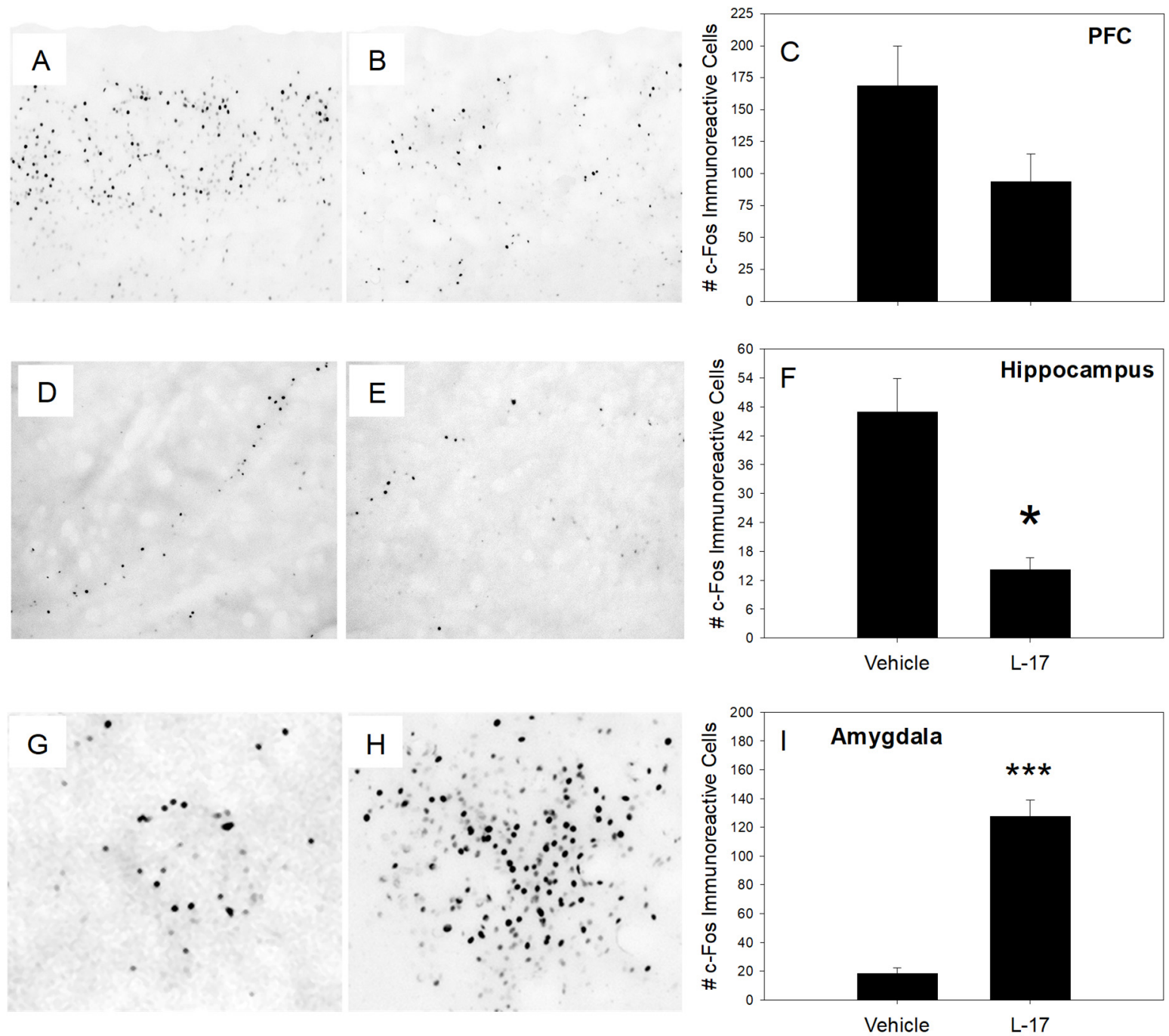

Figure 4. Representative sections illustrating the expression and distribution of c-Fos protein immunolabeled cells in the prefrontal cortex PFC, (A-C), hippocampus (D-F), and the central nucleus of the amygdala (G-I) in vehicle- and L-17-pretreated rats. ${ }^{*} p<0.05$ and ${ }^{* * *} p<0.001$, two-tailed Student's $t$-test.

Pretreatment with L-17 decreased c-Fos immunoreactivity in the hippocampus and increased it in the amygdala. The expression of c-Fos in the PFC was not statistically different between the groups. Summary quantitative assessments were performed from four vehicle- and four L-17-administered rats.

\subsection{In Vivo Electrophysiology}

The mean basal firing activity was $3.46 \pm 0.83 \mathrm{~Hz}$. L-17 (0.1-12 mg/ kg, i.v.) significantly and dose-dependently $\left(\mathrm{F}_{8,53}=4.84, p<0.001\right.$, ANOVA for repeated measures) inhibited the firing activity of 5-HT neurons, reaching a maximal $90 \%$ inhibition at $12 \mathrm{mg} / \mathrm{kg}$. WAY100135 partially reversed the L-17-induced inhibition of 5-HT neurons (Figure 5). 

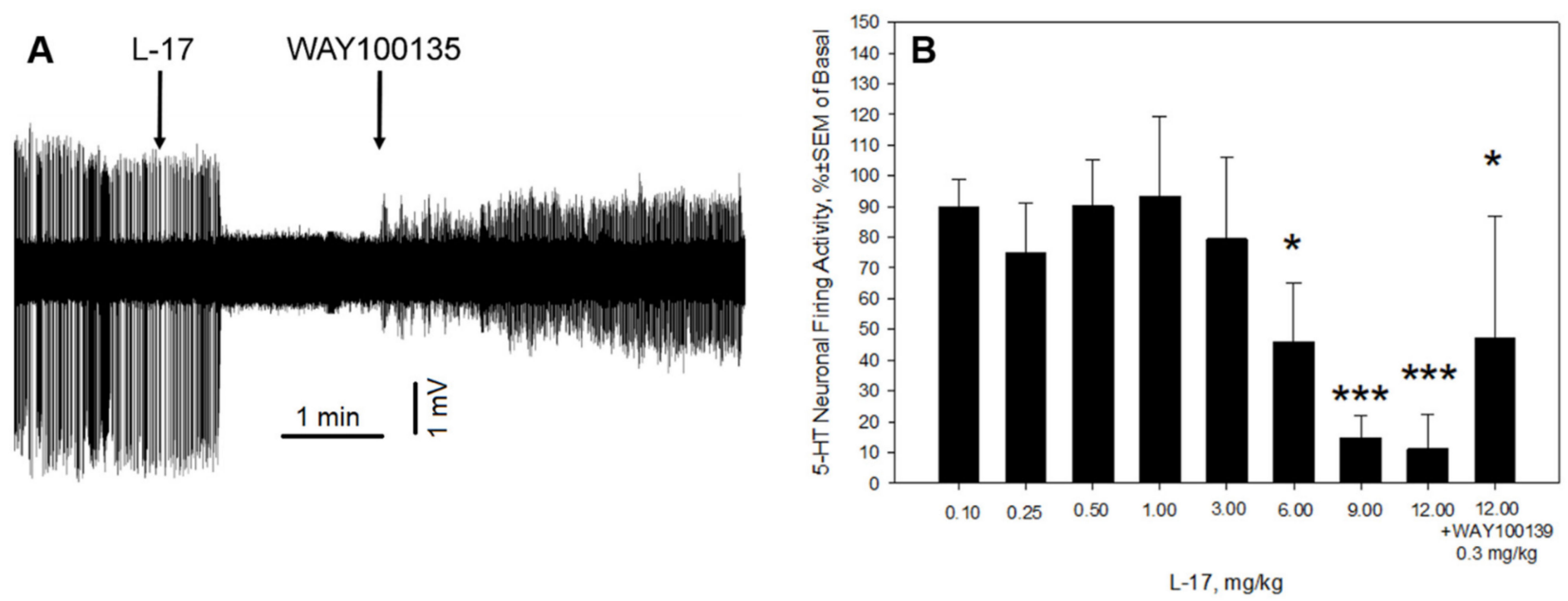

Figure 5. L-17 significantly and dose-dependently inhibited the firing activity of 5-HT neurons. (A): representative recording from a 5-HT neuron during L-17 (12 mg/kg) and WAY100135 (0.3 mg/kg) administration. (B): Summary effect of L-17 $(0.1-12 \mathrm{mg} / \mathrm{kg})$ and WAY100135 $(0.3 \mathrm{mg} / \mathrm{kg})$ on the spontaneous firing activity of 5-HT neurons of the DRN (data from 8 neurons from 7 rats). ${ }^{*} p<0.05$ and ${ }^{* * *} p<0.001$, Bonferroni post-hoc test.

\section{Discussion}

In this study, we performed a complex in silico assessment of the pharmacotherapeutic properties of L-17, as well as In Vivo electrophysiological assessment of the effect of this compound on the firing activity of 5-HT neurons in the rat DRN. PASS 10.4 Professional Extended [21] software predicted L-17 to have antidepressant-like properties. This prediction is consistent with the previously reported antidepressant-like effect of L-17 in rats [6]. PASS 10.4 Professional Extended also predicted that the antidepressant-like effect of L-17 can be explained, at least in part, via its 5-HT reuptake inhibition property.

AutoDock Vina 1.1.2 [23] docking energy assessment predicted that L-17 has an affinity to the SERT comparable to fluoxetine, $5-\mathrm{HT}_{3}$ binding affinity similar to granisetron, and $5-\mathrm{HT}_{1 \mathrm{~A}}$ binding affinity comparable to WAY100135. The prediction of the molecular interactions between $\mathrm{L}-17$ and the binding sites of SERT and $5-\mathrm{HT}_{3}$ and $5-\mathrm{HT}_{1 \mathrm{~A}}$ receptors with LigandScout 4.2.1 software [22] revealed that the mechanisms of L-17 binding to the SERT and 5- $\mathrm{HT}_{1 \mathrm{~A}}$ receptor are similar to fluoxetine and WAY100135, respectively. L-17 binding to $5-\mathrm{HT}_{3}$ receptors is completely different from that of granisetron. Consistently, the topographic poses of L-17 within SERT and 5- $\mathrm{HT}_{1 \mathrm{~A}}$ receptor binding sites are remarkably similar to those of fluoxetine and WAY100135, respectively. Thus, the morpholine cycle nitrogen atom of L-17 is engaged in a p- $\pi$ exchange with PHE2 69 of SERT. If protonated, this nitrogen forms a region of undirected electrostatic interaction. Two more structural elements of L-17 participate in five nonspecific hybrid interactions with TYR23, ALA97, ILE100, ALA101, and TYR104 of SERT. Fluoxetine is banded to SERT via the electrostatic interaction of the protonated $\mathrm{NH}_{2}$ group. Three additional groups of $\mathrm{L}-17$ form five hydrogen bonds with TYR23, ALA24, ASP26, and SER367x. Three more structural elements participate in six nonspecific hybrid interactions with ILE100, ALA101, TYR104, PHE269, LEU371, and VAL429. L-17 might bind to the 5-HT 3 receptor by stacking with PHE97. Two structural elements of L-17 participate in four nonspecific hybrid interactions with LEU93, PHE97, VAL100, and LEU123. No stacking is observed in granisetron binding to a $5-\mathrm{HT}_{3}$ receptor. Fixation is exerted by three nonspecific hydrophobic interactions with ILE38, TRP57, and TYR120. The morpholine cycle oxygen atom of L-17 forms a hydrogen bond with TYR366 of the $5-\mathrm{HT}_{3}$ receptor binding site. Two structural elements of $\mathrm{L}-17$ form three nonspecific hydrophobic links with TRP78, PHE88, and ILE89 of the 5-HT 3 receptor binding site. The protonated nitrogen atom of the morpholine cycle of WAY100135 exerts an electrostatic interaction with TYR366. Two WAY100135 molecule fragments participate 
in three nonspecific hydrophobic interactions with ALA69, TYR72, TRP78, ILE89, VAL93, ILE165, ALA179, PHE338, and LEU357 of the 5- $\mathrm{HT}_{3}$ receptor binding site.

It was demonstrated that pretreatment with L-17 robustly increased c-Fos immunoreactivity in the amygdala. The amygdala is a fundamental structure in emotional responses, including fear and anxiety [24]. Thus, it is possible that the modulation of amygdaloid neural excitability is involved in the therapeutic response to antidepressant, anxiolytic, and mood-stabilizing medicines. It has been reported that various CNS drugs, such as typical [12] and atypical antipsychotics [12-14], tricyclic antidepressants [13], and SSRIs $[13,15,16]$, increased c-Fos immunoreactivity in the amygdala, indicating an increased neural excitability in this brain area. In our previous studies, we found that pyridoindole derivate, SMe1EC2M3, a molecule with putative 5-HT reuptake inhibition properties and antidepressant-like behavioral effect [7], stimulated amygdaloid c-Fos immunoreactivity as well [11]. The finding that SSRI-induced amygdaloid c-Fos immunoreactivity was potentiated by an antagonist of $5-\mathrm{HT}_{1 \mathrm{~A}}$ autoreceptors indicated that the $5-\mathrm{HT}$ system is involved in the modulation of amygdaloid neural excitability by antidepressant drugs. Thus, it can be summarized that inducement of amygdaloid c-Fos immunoreactivity is an important marker for the putative mood-stabilizing and antidepressant-like effect, and the finding that L-17 stimulated proto-oncogene Fos expression in the amygdala provides additional support to the hypothesized beneficial effects of this molecule as a future CNS drug.

With regard to proto-oncogene Fos expression in other brain areas, we found that acute administration of L-17 significantly decreased c-Fos immunoreactivity in the hippocampus, and tended to decrease it in the PFC. It was previously reported that 5-HT depletion led to an increased c-Fos expression in these brain areas [20]. Thus, it is possible that the L-17-induced decrease in forebrain c-Fos immunoreactivity might be explained by the ability of this drug to elevate extracellular 5-HT concentrations. Further studies should, however, be performed to test this hypothesis.

We found that acute intravenous administration of L-17 significantly and dosedependently inhibited the firing activity of 5-HT neurons of the DRN. Similar inhibitory effects on 5-HT neuronal firing activity have been observed with other SSRIs, such as citalopram [25], escitalopram [25,26], Wf-516 [27], or paroxetine [28]. Similar to observations of other SSRIs, the L-17-induced inhibition of 5-HT neuronal firing activity was reversed by WAY100135. It is likely that L-17 acts as a potent SERT blocker. Inhibition of SERT by acute levels L-17 leads to an increase in the extracellular 5-HT levels, activation of $5-\mathrm{HT}_{1 \mathrm{~A}}$ autoreceptors, and reduction in the firing activity of 5-HT neurons. The subsequent blockade of 5- $\mathrm{HT}_{1 \mathrm{~A}}$ autoreceptors reverses the inhibition of 5-HT neurons.

Unlike escitalopram-induced suppression of 5-HT neuronal firing activity, which was completely reversed by $0.1 \mathrm{mg} / \mathrm{kg}$ of WAY100135 [25,26], the L-17-induced inhibition of 5-HT neurons was only partially reversed by WAY100135, even though WAY100135 was administered at $0.3 \mathrm{mg} / \mathrm{kg}$. Thus, it is possible that L- 17 interacts with a molecular target (s) other than SERTs. One of these targets predicted by in silico tests is 5-HT receptors. It is possible that L-17 acts, in addition to its function as a SERT blocker, as a partial agonist of 5-HT $\mathrm{HT}_{1 \mathrm{~A}}$ receptors. The competition between $\mathrm{L}-17$ and WAY100135 on 5- $\mathrm{HT}_{1 \mathrm{~A}}$ receptors putatively prevents complete WAY100135-mediated recovery of the firing activity of 5-HT neurons. Another possibility might be, however, a direct interaction of L-17 with $\alpha_{1}$-adrenoceptors [29].

In summary, the antidepressant-like properties of L-17 reported in previous studies can be explained, at least in part, by the ability of this compound to modulate central 5-HT neurotransmission. We cannot, however, exclude the interaction of L-17 with receptors modulating the excitability of 5-HT neurons, such as $5-\mathrm{HT}_{1 \mathrm{~A}}, 5-\mathrm{HT}_{3}$, and/or $\alpha_{1 / 2}$-adrenergic receptors. It is also possible that L-17 directly interacts with other neurotransmitter systems, such as norepinephrinergic, dopaminergic, and/or histaminergic ones. The L-17-induced modulation of 5-HT transmission is likely to be mediated, at least in part, via the inhibition of 5-HT reuptake and partial antagonism to $5-\mathrm{HT}_{1 \mathrm{~A}}$ receptors. L-17-induced increase in 5-HT transmission putatively results in increased neuronal ex- 
citability in the amygdala and decreased neuronal firing activity in the hippocampus. These L-17-induced changes in neural excitability across the brain might be involved in the neuroprotective and antidepressant-like behavioral effects of this compound reported in previous studies. The previously reported antidepressant-like properties of L-17, and its modulatory effect on 5-HT neurons of the DRN and on neural excitability in the amygdala and the hippocampus, reported in this study, suggest that L-17 might be an effective antidepressant drug. Since L-17 also possesses neuro- and cardioprotective properties, it could be useful in affective illness development due to general medical condition, such as post-stroke and post-MI depression. It should be also stated that the combined in silico (computerized prediction of molecular binding mechanisms), Ex Vivo (assessment of neuronal excitability using c-Fos immunoreactivity measurement), and In Vivo (direct assessment of the excitability of monoamine-secreting neurons) investigation might be a useful strategy for early preclinical assessment of the efficacy and neural mechanism of action of novel CNS drugs. In this specific study, the usage of in silico prediction techniques allowed us to forecast the SERT- and 5- $\mathrm{HT}_{1 \mathrm{~A} / 3}$-receptor-mediated antidepressant effect of L-17. The predicted 5-HT reuptake inhibitory effect of L-17 was confirmed by In Vivo electrophysiology, and the putative 5-HT-mediated effect on neural excitability in the amygdala and hippocampus by the c-Fos expression assessment.

\section{Materials and Methods}

\subsection{In Silico Predictions}

Using PASS 10.4 Professional Extended software (Institute of Biomedical Chemistry, Moscow, Russia) [21], the presence (Pa) or absence (Pi) probability of 480 systemic types of pharmacotherapeutic activity was calculated. Promising activities were those with $\mathrm{Pa} \geq 0.1$ and $\mathrm{Pa} / \mathrm{Pi} \geq 1.0$.

Furthermore, for a comparative evaluation of the L-17 compound's affinity to the selected biotargets, the docking of the compound to the specific binding sites of these proteins was performed. Five experimental X-ray 3D models of SERT were obtained from Protein Data Bank in Europe [30]. Among these five models, the longest one (PDB code 5I6X), with the maximum resolution including an inhibitor, was chosen to allow the unambiguous determination of the binding site position [31]. The experimental 3D models for 5- $\mathrm{HT}_{3}$ and $5-\mathrm{HT}_{1 \mathrm{~A}}$ receptors were not available from Protein Data Bank in Europe; therefore, a search for the best theoretical 3D models from the Database of Comparative Protein Structure Models [32] was conducted. Among the available models, the longest ones, with the highest statistical significance, were selected for $5-\mathrm{HT}_{3}[33]$ and $5-\mathrm{HT}_{1 \mathrm{~A}}$ [34] receptors.

The 3D models of L-17 and reference molecules were constructed using the molecular mechanics methods in MarvinSketch15.6.15 software (Chemaxon, Budapest, Hungary) [35], followed by optimization with the semi-empirical quantum chemical method PM7 in MOPAC2016 software (James Stewart, Colorado Springs, CO, USA) [36]. Granisetron, WAY100135, and fluoxetine were chosen as reference molecules since they are well-known as blockers of 5- $\mathrm{HT}_{3}$ and $5-\mathrm{HT}_{1 \mathrm{~A}}$ receptors and SERTs, respectively. Fluoxetine is also one of the most widely used antidepressant drugs. The docking was performed using AutoDock Vina 1.1.2 [23], five times for each compound into each target, and then the spectrum of energies was used to determine their minimum binding energies. To reveal the mechanisms of serotoninergic action of the L-17 compound, an analysis of its affinity spectrum in comparison with the affinity spectra of reference compounds was performed. The primary information about the reference compounds for the target proteins was obtained from the UniProtKB database [37]. For each reference compound found in UniProtKB, the mechanism of its action was clarified using DrugBank [38]. In the case that information in UniProtKB and DrugBank datasets was not sufficient, the search for references was performed in the IUPHAR database of pharmacologically relevant proteins and their ligands [39]. The SSRI fluoxetine and the selective antagonists of $5-\mathrm{HT}_{3}$ (granisetron) and 
5-HT $1 \mathrm{~A}$ (WAY100135) receptors were used as reference molecules. Using the obtained energy spectra of $\Delta \mathrm{E}$, the $\mathrm{pK}$ values were calculated using the formula:

$$
p K=-\lg e^{-\Delta E / R T}
$$

where $R$ is the universal gas constant $\left(8.314 \mathrm{~J} \times \mathrm{mol}^{-1} \times \mathrm{K}^{-1}\right)$ and $T$ is the temperature, set as $300 \mathrm{~K}$. The molecular binding mechanism of L-17, granisetron, and WAY100135 with SERT and with 5- $\mathrm{HT}_{3}$ and 5- $\mathrm{HT}_{1 \mathrm{~A}}$ receptors was further evaluated using LigandScout 4.2.1 software [22]. The data on binding sites were found in the available literature. For SERT, the key amino acids of the binding site are Gly94, Ala96, Val97, Asn101, Ser336, Asn368, Leu434, Asp437, and Ser438 [31]. For the 5- $\mathrm{HT}_{3}$ receptor, the key amino acids of the binding site are Tyr229, Phe221, Asn123, Trp85, Trp178, Tyr148, Arg87, Gln146, and Tyr138 [33]. For the $5 \mathrm{HT}_{1 \mathrm{~A}}$ receptor, the key amino acids of the binding site are Tyr56, Gln57, Asp76, Val77, Ser159, Trp318, Phe321, Phe322, Thr339, Gly342, Ala343, Ile345, and Asn346 [34].

\subsection{Assessment of c-Fos Immunoreactivity}

For the assessment of the proto-oncogene c-Fos expression, rats were pretreated with L-17 $(60 \mathrm{mg} / \mathrm{kg}$, intraperitoneally, i.p.) twenty-four hours and one hour before immunoreactivity measurements. Expression of c-Fos was analyzed, as we reported previously [11,40]. The rats were anesthetized by a combined treatment of zoletil $(30 \mathrm{mg} / \mathrm{kg}$, Virbac, Carros, France) and xylariem (15 mg/kg, Riemser Pharma GmbH, Greifswald, Germany) in volumes of $0.1 \mathrm{~mL}$ and $0.24 \mathrm{~mL} / 300 \mathrm{~g}$ b.w., respectively. Then, they were perfused transcardially with $50 \mathrm{~mL}$ of cold isotonic saline containing $150 \mu \mathrm{L}$ of heparin $(5000 \mathrm{IU} / \mathrm{mL}$, Zentiva, Hlohovec, Slovakia) followed by $200 \mathrm{~mL}$ of fixative containing $4 \%$ paraformaldehyde (Sigma-Aldrich, Germany) in 0.1 M phosphate buffer (PB, pH 7.4). Immediately after perfusion, the brains were removed from the skulls, postfixed in a fresh fixative overnight, washed in $0.1 \mathrm{M} \mathrm{PB}$ at $4{ }^{\circ} \mathrm{C}$ overnight, and infiltrated with $30 \%$ sucrose (Slavus, Podunajské Biskupice, Slovakia) at $4{ }^{\circ} \mathrm{C}$ for $48 \mathrm{~h}$. Coronal sections of $35 \mu \mathrm{m}$ thickness were alternatively cut over the whole brain in a cryocut (Hyrax C-50). The sections were repeatedly washed in $0.1 \mathrm{M} \mathrm{PB}$ and pretreated with $0.3 \% \mathrm{H}_{2} \mathrm{O}_{2}$ (Sigma-Aldrich, Munich, Germany) in $0.1 \mathrm{M}$ $\mathrm{PB}$ for $10 \mathrm{~min}$ at room temperature (RT). Thereafter, the sections were rinsed $3 \times 10 \mathrm{~min}$ in $0.1 \mathrm{M}$ PB and exposed to rabbit anti-Fos polyclonal antibody (1:2000) in $0.1 \mathrm{M}$ PB containing $4 \%$ normal goat serum (Gibco, Grand Island, NY, USA), 0.5\% Triton X-100 (Sigma-Aldrich, Munich, Germany), and $0.1 \%$ sodium azide (Sigma-Aldrich, Munich, Germany) for $48 \mathrm{~h}$ at RT. After several rinses in $\mathrm{PB}$, the sections were incubated with biotinylated goat anti-rabbit IgG (1:500, BA-9200, VectorStain Elite ABC Kit, Vector Laboratories, Burlingame, CA, USA) in PB for 90 min at RT. Next, the PB rinsing was followed by incubation with the avidinbiotin-peroxidase complex (1:250) for $90 \mathrm{~min}$ at RT. After several washes in $0.05 \mathrm{M}$ sodium acetate buffer ( $\mathrm{SAB}, \mathrm{pH}$ 6.0), c-Fos-antigenic sites were visualized by 3,3'-diaminobenzidine tetrahydrochloride $(0.0625 \% \mathrm{DAB})$ enhanced with $2.5 \%$ nickel chloride (Sigma-Aldrich, Munich, Germany), in SAB containing $0.0006 \% \mathrm{H}_{2} \mathrm{O}_{2}$. Developing time was 6-8 $\mathrm{min}$. The heavy metal intensification of DAB yielded black staining of c-Fos-labeled nuclei.

The topographic mapping of the c-Fos protein immunolabeled cells was performed in three brain areas (PFC, hippocampus, and central nucleus of the amygdala), identified based on the rat brain atlas [11,41]. The individual structures investigated were captured unilaterally from 6-10 representative sections using an Axio Imager A1 light microscope (Carl Zeiss, Jena, Germany) coupled to a video camera and monitor. Since the staining of each individual Fos-immunoreactive cell varied from very intense to very light, c-Fos profile counting was performed on pictures inverted by the Adobe Photoshop 7.0 "invert" adjustment to achieve white c-Fos profiles on a black background. The counting of the c-Fos profiles was performed manually on a PC computer by a person blind to the design of the experiment.

\subsection{In Vivo Electrophysiology}

In Vivo electrophysiological assessment of the excitability of 5-HT neurons of the DRN was performed as previously described $[7,26,42,43]$. Adult male Wistar rats, weighing 
300-350 g, were ordered from the Animal Breeding Facility of The Institute of Experimental Pharmacology and Toxicology, Center of Experimental Medicine, Slovak Academy of Sciences in Dobrá Voda, Slovakia. Rats were anesthetized with chloral hydrate $(0.4 \mathrm{~g} / \mathrm{kg}$, intraperitoneally, i.p., Lambda Life s.r.o., Bratislava, Slovakia;) and maintained in a stereotaxic frame (David Kopf Instruments, Tujunga, CA, USA). Rat body temperature was maintained between 36 and $37^{\circ} \mathrm{C}$ with a heating pad (Gaymor Instruments, Orchard Park, NY, USA). The scalp was opened, and a $3 \mathrm{~mm}$ hole was drilled in the skull for insertion of electrodes. Glass pipettes were pulled with a DMZ Universal Electrode Puller (Zeitz-Instruments $\mathrm{GmbH}$, Martinsried, Germany) to a fine tip approximately $1 \mu \mathrm{m}$ in diameter and filled with $2 \mathrm{M} \mathrm{NaCl}$ solution. Electrode impedance ranged from 4 to $6 \mathrm{M} \Omega$. The pipettes were lowered into the DRN (7.8-8.3 $\mathrm{mm}$ posterior to bregma and 4.5-7.0 $\mathrm{mm}$ ventral to brain surface) [41] with a David Kopf Instruments hydraulic micro-positioner. The action potentials generated by 5-HT neurons were recorded using the ADInstruments Extracellular Recording System (Dunedin, New Zealand). The 5-HT neurons were identified by bi- or tri-phasic action potentials with a rising phase of long duration and regular firing rate of $0.5-5.0 \mathrm{~Hz}$ [44]. All experimental procedures were approved by the Animal Health and Animal Welfare Division of the State Veterinary and Food Administration of the Slovak Republic (Permit number Ro 3592/15-221) and conformed to Directive 2010/63/EU of the European Parliament and the Council on the Protection of Animals Used for Scientific Purposes.

Author Contributions: Conceptualization, A.S. (Alexey Sarapultsev), P.V., D.G., A.K. (Alexander Kiss), M.M., J.O., P.S., O.C., A.S. (Alexander Spasov) and E.D.; bioinformatics, A.S. (Alexey Sarapultsev), P.V. and A.K. (Andrey Kochetkov); synthesis, L.S.; ex vivo experiments, J.O. and A.B.; in vivo experiments, D.G. and R.P.; writing—original draft preparation, A.S. (Alexey Sarapultsev), P.V., D.G., R.P., M.R. and E.D.; writing-review and editing, A.S. (Alexey Sarapultsev), P.V., D.G., A.K. (Andrey Kochetkov), A.K. (Alexander Kiss), M.M., M.R., P.S., O.C., A.S. (Alexander Spasov) and E.D.; funding acquisition, A.S. (Alexey Sarapultsev) and E.D. All authors have read and agreed to the published version of the manuscript.

Funding: The work of the authors of this study was supported by the Slovak Research and Development Agency (contract APVV-19-0435), Scientific Grant Agency of the Ministry of Education of the Slovak Republic, the Slovak Academy of Sciences (grant VEGA 2/0046/18), and a Government Contract of the Russian Federation with the Institute of Immunology and Physiology (AAAA-A18118020690020-1).

Institutional Review Board Statement: Not applicable.

Informed Consent Statement: Not applicable.

Data Availability Statement: The original research data is avaliable upon requet.

Conflicts of Interest: The authors declare no conflict of interest.

\section{Abbreviations}

$\begin{array}{ll}\text { 3D } & \text { Three-dimensional } \\ 5-\mathrm{HT} & \text { 5-hydroxytryptamine (serotonin) } \\ 5-\mathrm{HT}_{1 \mathrm{~A}} \mathrm{R} & 5-\mathrm{HT}_{1 \mathrm{~A}} \text { Receptor } \\ 5-\mathrm{HT}_{3} \mathrm{R} & 5-\mathrm{HT}_{3} \text { Receptor } \\ \text { ANOVA } & \text { Analysis of variance }_{\text {DRN }} \text { Dorsal raphe nucleus } \\ \text { L-17 } & \text { 2-morpholino-5-phenyl-6H-1,3,4-thiadiazine, hydrobromide } \\ \text { MI } & \text { Myocardial infarction } \\ \text { SERT } & \text { Serotonin transporter } \\ \text { SSRI } & \text { Selective serotonin reuptake inhibitor }\end{array}$




\section{References}

1. Sarapultsev, A.P.; Chupakhin, O.N.; Sarapultsev, P.A.; Sidorova, L.P.; Tseitler, T.A. Pharmacologic Evaluation of Antidepressant Activity and Synthesis of 2-Morpholino-5-phenyl-6H-1,3,4-thiadiazine Hydrobromide. Pharmaceuticals 2016, 9, 27. [CrossRef]

2. Sarapultsev, P.; Chupakhin, O.; Sarapultsev, A.; Rantsev, M.; Sidorova, L.; Medvedeva, S.; Danilova, I. New insights in to the treatment of myocardial infarction. Int. J. Exp. Pathol. 2012, 93, 18-23. [CrossRef] [PubMed]

3. Sarapultsev, A.P.; Chupakhin, O.N.; Sarapultsev, P.A.; Rantsev, M.A.; Medvedeva, S.U.; Sidorova, L.P. Effect of a new class of compounds of the group of substituted 5R1,6H2-1,3,4-thiadiazine-2-amines on the inflammatory and cytokine response in experimental myocardial infarction. Curr. Vasc. Pharmacol. 2015, 13, 43-53. [CrossRef] [PubMed]

4. Sarapultsev, A.P.; Chupakhin, O.N.; Sarapultsev, P.A.; Rantsev, M.A.; Medvedeva, S.U.; Sidorova, L.P.; Abidov, M.T.; Danilova, I.G. Modulation of inflammatory response improves myocardial infarct healing in rats. Curr. Pharm. Des. 2014, 20, 1980-1986. [CrossRef]

5. Sarapultsev, A.; Chupakhin, O.; Rantsev, M.; Sarapultsev, P.; Danilova, I.; Medvedeva, S.; Sidorova, L.; Tseitler, T.; Brilliant, S.; Tseillikman, V. Effects of 1,3,4-thiadiazine compound with antidepressant properties in ligation model of acute pancreatitis. Gen. Physiol. Biophys. 2018, 37, 549-562. [CrossRef] [PubMed]

6. Shevelev, O.B.; Illarionova, N.B.; Petrovski, D.V.; Sarapultsev, A.P.; Chupakhin, O.N.; Moshkin, M.P. Effects of a compound from the group of substituted thiadiazines with hypothermia inducing properties on brain metabolism in rats, a study in vivo and in vitro. PLoS ONE 2017, 12, e0180739. [CrossRef] [PubMed]

7. Koprdova, R.; Csatlosova, K.; Durisova, B.; Bogi, E.; Majekova, M.; Dremencov, E.; Mach, M. Electrophysiology and Behavioral Assessment of the New Molecule SMe1EC2M3 as a Representative of the Future Class of Triple Reuptake Inhibitors. Molecules 2019, 24, 14. [CrossRef] [PubMed]

8. Bullitt, E. Expression of c-fos-like protein as a marker for neuronal activity following noxious stimulation in the rat. J. Comp. Neurol. 1990, 296, 517-530. [CrossRef] [PubMed]

9. Herdegen, T.; Leah, J.D. Inducible and constitutive transcription factors in the mammalian nervous system: Control of gene expression by Jun, Fos and Krox, and CREB/ATF proteins. Brain Res. Brain Res. Rev. 1998, 28, 370-490. [CrossRef]

10. Slattery, D.A.; Morrow, J.A.; Hudson, A.L.; Hill, D.R.; Nutt, D.J.; Henry, B. Comparison of alterations in c-Fos and Egr-1 (zif268) expression throughout the rat brain following acute administration of different classes of antidepressant compounds. Neuropsychopharmacology 2005, 30, 1278-1287. [CrossRef] [PubMed]

11. Koprdova, R.; Osacka, J.; Mach, M.; Kiss, A. Acute Impact of Selected Pyridoindole Derivatives on Fos Expression in Different Structures of the Rat Brain. Cell. Mol. Neurobiol. 2018, 38, 171-180. [CrossRef] [PubMed]

12. Cohen, B.M.; Cherkerzian, S.; Ma, J.; Ye, N.; Wager, C.; Lange, N. Cells in midline thalamus, central amygdala, and nucleus accumbens responding specifically to antipsychotic drugs. Psychopharmacology 2003, 167, 403-410. [CrossRef] [PubMed]

13. Morelli, M.; Pinna, A. Antidepressants and atypical neuroleptics induce Fos-like immunoreactivity in the central extended amygdala. Ann. N. Y. Acad. Sci. 1999, 877, 703-706. [CrossRef] [PubMed]

14. Pinna, A.; Costa, G.; Contu, L.; Morelli, M. Fos expression induced by olanzapine and risperidone in the central extended amygdala. Eur. J. Pharmacol. 2019, 865, 172764. [CrossRef] [PubMed]

15. Thomsen, C.; Helboe, L. Regional pattern of binding and c-Fos induction by (R)- and (S)-citalopram in rat brain. Neuroreport 2003, 14, 2411-2414. [CrossRef] [PubMed]

16. Hayashi, T.; Miyata, M.; Nagata, T.; Izawa, Y.; Kawakami, Y. Intracerebroventricular fluvoxamine administration inhibited pain behavior but increased Fos expression in affective pain pathways. Pharmacol. Biochem. Behav. 2009, 91, 441-446. [CrossRef]

17. Jongsma, M.E.; Sebens, J.B.; Bosker, F.J.; Korf, J. Effect of 5-HT1A receptor-mediated serotonin augmentation on Fos immunoreactivity in rat brain. Eur. J. Pharm. 2002, 455, 109-115. [CrossRef]

18. Robertson, G.S.; Fibiger, H.C. Effects of olanzapine on regional C-Fos expression in rat forebrain. Neuropsychopharmacology 1996, 14, 105-110. [CrossRef]

19. Sebens, J.B.; Koch, T.; Ter Horst, G.J.; Korf, J. Olanzapine-induced Fos expression in the rat forebrain; cross-tolerance with haloperidol and clozapine. Eur. J. Pharm. 1998, 353, 13-21. [CrossRef]

20. Kornum, B.R.; Weikop, P.; Moller, A.; Ronn, L.C.; Knudsen, G.M.; Aznar, S. Serotonin depletion results in a decrease of the neuronal activation caused by rivastigmine in the rat hippocampus. Brain Res. 2006, 1073-1074, 262-268. [CrossRef]

21. Filimonov, D.A.; Lagunin, A.A.; Gloriozova, T.A.; Rudik, A.V.; Druzhilovskii, D.S.; Pogodin, P.V.; Poroikov, V.V. Prediction of the Biological Activity Spectra of Organic Compounds Using the Pass Online Web Resource. Chem. Heterocycl. Compd. 2014, 50, 444-457. [CrossRef]

22. Inte:Ligand: Your Partner for in Silico Drug Discovery. Available online: http://www.inteligand.com/ (accessed on 15 December 2021).

23. Trott, O.; Olson, A.J. AutoDock Vina: Improving the speed and accuracy of docking with a new scoring function, efficient optimization, and multithreading. J. Comput. Chem. 2010, 31, 455-461. [CrossRef] [PubMed]

24. Amunts, K.; Kedo, O.; Kindler, M.; Pieperhoff, P.; Mohlberg, H.; Shah, N.J.; Habel, U.; Schneider, F.; Zilles, K. Cytoarchitectonic mapping of the human amygdala, hippocampal region and entorhinal cortex: Intersubject variability and probability maps. Anat. Embryol. 2005, 210, 343-352. [CrossRef] [PubMed] 
25. El Mansari, M.; Sánchez, C.; Chouvet, G.; Renaud, B.; Haddjeri, N. Effects of acute and long-term administration of escitalopram and citalopram on serotonin neurotransmission: An in vivo electrophysiological study in rat brain. Neuropsychopharmacology 2005, 30, 1269-1277. [CrossRef]

26. Dremencov, E.; Csatlosova, K.; Durisova, B.; Moravcikova, L.; Lacinova, L.; Jezova, D. Effect of Physical Exercise and Acute Escitalopram on the Excitability of Brain Monoamine Neur ons: In Vivo Electrophysiological Study in Rats. Int. J. Neuropsychopharmacol. 2017, 20, 585-592. [CrossRef] [PubMed]

27. El Mansari, M.; Blier, P. In vivo electrophysiological assessment of the putative antidepressant Wf-516 in the rat raphe dorsalis, locus coeruleus and hippocampus. Naunyn-Schmiedebergs Arch. Pharmacol. 2008, 376, 351-361. [CrossRef]

28. Piñeyro, G.; Blier, P.; Dennis, T.; de Montigny, C. Desensitization of the neuronal 5-HT carrier following its long-term blockade. J. Neurosci. Off. J. Soc. Neurosci. 1994, 14 Pt 2, 3036-3047. [CrossRef]

29. Dremencov, E.; El Mansari, M.; Blier, P. Distinct electrophysiological effects of paliperidone and risperidone on the firing activity of rat serotonin and norepinephrine neurons. Psychopharmacology 2007, 194, 63-72. [CrossRef]

30. PDBe logo Protein Data Bank in Europe. Available online: https://www.ebi.ac.uk/pdbe/ (accessed on 15 December 2021).

31. Coleman, J.A.; Green, E.M.; Gouaux, E. X-ray structures and mechanism of the human serotonin transporter. Nature 2016, 532, 334-339. [CrossRef]

32. ModBase: Database of Comparative Protein Structure Models. Available online: https://modbase.compbio.ucsf.edu/modbasecgi/index.cgi (accessed on 15 December 2021).

33. Price, K.L.; Lillestol, R.K.; Ulens, C.; Lummis, S.C.R. Palonosetron-5-HT3 Receptor Interactions As Shown by a Binding Protein Cocrystal Structure. ACS Chem. Neurosci. 2016, 7, 1641-1646. [CrossRef]

34. Jaśkowska, J.; Zaręba, P.; Śliwa, P.; Pindelska, E.; Satała, G.; Majka, Z. Microwave-Assisted Synthesis of Trazodone and Its Derivatives as New 5-HT(1A) Ligands: Binding and Docking Studies. Molecules 2019, 24, 1609. [CrossRef]

35. MarvinSketch-Create and Design. Available online: https:// chemaxon.com/products/marvin (accessed on 15 December 2021).

36. Stewart Computational Chemistry. Available online: http://openmopac.net/ (accessed on 15 December 2021).

37. UniProtKB. Available online: https:/ / www.uniprot.org/help/uniprotkb (accessed on 15 December 2021).

38. DrugBank Online. Available online: https://go.drugbank.com/ (accessed on 15 December 2021).

39. IUPHAR/BPS Guide to PHARMACOLOGY. Available online: https://www.guidetopharmacology.org/ (accessed on 15 December 2021).

40. Majercikova, Z.; Weering, H.; Scsukova, S.; Mikkelsen, J.D.; Kiss, A. A new approach of light microscopic immunohistochemical triple-staining: Combination of Fos labeling with diaminobenzidine-nickel and neuropeptides labeled with Alexa488 and Alexa555 fluorescent dyes. Endocr. Regul. 2012, 46, 217-223. [CrossRef] [PubMed]

41. Paxinos, G.; Watson, C. Paxino's and Watson's The Rat Brain in Stereotaxic Coordinates, 7th ed.; Elsevier: Amsterdam, The Netherlands, 2014.

42. Csatlosova, K.; Bogi, E.; Durisova, B.; Grinchii, D.; Paliokha, R.; Moravcikova, L.; Lacinova, L.; Jezova, D.; Dremencov, E. Maternal immune activation in rats attenuates the excitability of monoamine-secreting neurons in adult offspring in a sex-specific way. Eur. Neuropsychopharmacol. 2020, 43, 82-91. [CrossRef] [PubMed]

43. Grinchii, D.; Paliokha, R.; Tseilikman, V.; Dremencov, E. Inhibition of cytochrome P450 by proadifen diminishes the excitability of brain serotonin neurons in rats. Gen. Physiol. Biophys. 2018, 37, 711-713. [CrossRef] [PubMed]

44. Vandermaelen, C.P.; Aghajanian, G.K. Electrophysiological and pharmacological characterization of serotonergic dorsal raphe neurons recorded extracellularly and intracellularly in rat brain slices. Brain Res. 1983, 289, 109-119. [CrossRef] 